\title{
Effectiveness of pharmacologic therapies on smoking cessation success: three years results of a smoking cessation clinic
}

\author{
Elif Yilmazel Ucar ${ }^{1,2 *}$, Omer Araz ${ }^{1}$, Nafiye Yilmaz ${ }^{1}$, Metin Akgun ${ }^{1}$, Mehmet Meral ${ }^{1}$, Hasan Kaynar ${ }^{1}$ and Leyla Saglam
}

\begin{abstract}
Background: Pharmacologic therapies have an important role in the success of interventions for smoking cessation. This study aims to determine the efficacy of several pharmacologic treatments in patients who applied to a smoking cessation clinic.

Methods: This retrospective study includes 422 patients who presented to our smoking cessation clinic between January 2010 and June 2013, used the pharmacologic treatment as prescribed and completed the one-year follow-up period. All patients were assessed using the Fagerström Test for Nicotine Dependence (FTND) and received both behavioral therapy and pharmacotherapy. Patients' smoking status at one year was assessed by telephone interview.

Results: The patients were $24.3 \%$ female (103/422) and 75.7\% male (319/422) with a mean age of $38 \pm 10$ years. Patients were divided into three groups: varenicline (166 patients), bupropion (148 patients) and nicotine replacement therapy (108 patients).

The smoking cessation rates of these groups were $32.5 \%, 23 \%$ and $52.8 \%$, respectively, and were statistically significant $(p<0.001)$. The overall success rate was $35 \%$. Further analysis revealed that pharmacologic therapy $(p<0.001)$ and gender $(p=0.01)$ were factors that showed statistically significant effects on smoking cessation rates. Males had higher success rates than females. The overall relapse rate was $21.6 \%$ and the bupropion group showed the highest relapse rate among treatment groups. Lack of determination emerged as the most important factor leading to relapse.
\end{abstract}

Conclusion: Nicotine replacement therapy was found to be more effective at promoting abstinence from smoking than other pharmacologic therapies.

Keywords: Effectiveness, Pharmacologic therapy, Quit rate, Smoking cessation

\section{Background}

Smoking is the leading cause of preventable morbidity and mortality worldwide $[1,2]$. Smoking cessation significantly improves life expectancy, decreases morbidity, and reduces healthcare costs associated with smokingrelated conditions [3]. Interventions that include both counseling and pharmacotherapy appear to be the most effective, and success is more likely with more intensive interventions $[4,5]$.

\footnotetext{
* Correspondence: eucar1979@yahoo.com

'Department of Pulmonary Diseases, Ataturk University School of Medicine, Erzurum, Turkey

${ }^{2}$ Yakutiye Medical Research Center, Chest Disease Department, Erzurum, Yakutiye 25240, Turkey

Full list of author information is available at the end of the article
}

There are several pharmacological interventions available to aid smoking cessation [6]. The Food and Drug Administration (FDA) has approved seven medications for this purpose: five nicotine replacement therapies (NRT), bupropion and varenicline. In addition, the antihypertensive medication clonidine and the tricyclic antidepressant nortriptyline are sometimes used as second-line agents for smoking cessation, but their use is not FDA approved for this indication [7]. The most widely used product in Europe and the United States is NRT, which increases smoking cessation rates at one year by approximately 70\% [6,8]. Clinical trials have demonstrated statistically significant improvement in smoking cessation with varenicline and bupropion $[9,10]$. 
The aim of this study was to evaluate the efficacy of NRT, varenicline and bupropion for smoking cessation.

\section{Methods}

\section{Study population}

Four hundred and twenty-two active smokers who presented to Ataturk University smoking cessation clinic between January 2010 and June 2013, received pharmacological therapy, and completed one year follow up, were included in the study. Patients who did not attend follow up visits, did not use their medication regularly as prescribed or were not available for a phone interview at the end of the one-year follow up were excluded from the study.

\section{Study design}

In this retrospective study, data were collected by reviewing medical records in an existing clinical database. All demographic, clinical and laboratory findings, results of the Fagerström Test for Nicotine Dependence (FTND), as well as treatment choices and their outcomes, were recorded. Patients were categorized into three treatment groups: varenicline, sustained-release bupropion and NRT, which included nicotine patch and nicotine gum. In addition to one of these supporting drugs, all patients underwent behavioral therapy. The local ethics committee of Ataturk University, Faculty of Medicine approved the protocol of the study.

\section{Pharmacological regimen}

In the NRT group, the 24-hour nicotine patch delivery system was used to aid smoking cessation. Subjects who smoked more than 20 cigarettes per day (CPD) began with a $21 \mathrm{mg} / \mathrm{d}$ nicotine patch for the first two weeks, $14 \mathrm{mg} / \mathrm{d}$ in weeks three to six and $7 \mathrm{mg} / \mathrm{d}$ in weeks seven to twelve. Nicotine gum was used when needed to fight cravings. In the varenicline group, patients received $0.5 \mathrm{mg} / \mathrm{d}$ varenicline for three days, followed by $1 \mathrm{mg} / \mathrm{d}$ ( $0.5 \mathrm{mg}$ twice daily) for four days. On day 8 , the target quit date, the varenicline dose was increased to $1 \mathrm{mg}$ twice daily. The duration of treatment was a total of 12 weeks. In the bupropion group, patients received sustained-release bupropion at $150 \mathrm{mg} / \mathrm{d}$ for three days, then $150 \mathrm{mg}$ twice daily for the remaining 12 -weeks.

\section{Definition of relapse}

To resume smoking after 3 months or more of smoking cessation.

\section{Statistical analysis}

Statistical analysis was performed with SPSS for Windows version 17.0 (SPSS Inc., Chicago, USA). Data were expressed as percentage, mean and standard deviation, odds ratio and 95\% confidence interval. We used Pearson Chi square test for comparisons of nominal variables and ANOVA for numeric variables. We performed an analysis adjustment for confounders using logistic regression. Findings were considered statistically significant at $\mathrm{p}<0.05$.

\section{Results}

From January 2010 to June 2013, a total of 675 patients were assessed and 422 out of them, 103 (24.3\%) females and 319 (75.7\%) males (mean age: $38 \pm 10 \mathrm{SD}$ ) with active smoking were included in the study. Out of these, 166 (38\%) received varenicline, 148 (35\%) bupropion and 108 (27\%) NRT (Figure 1). There was a significant

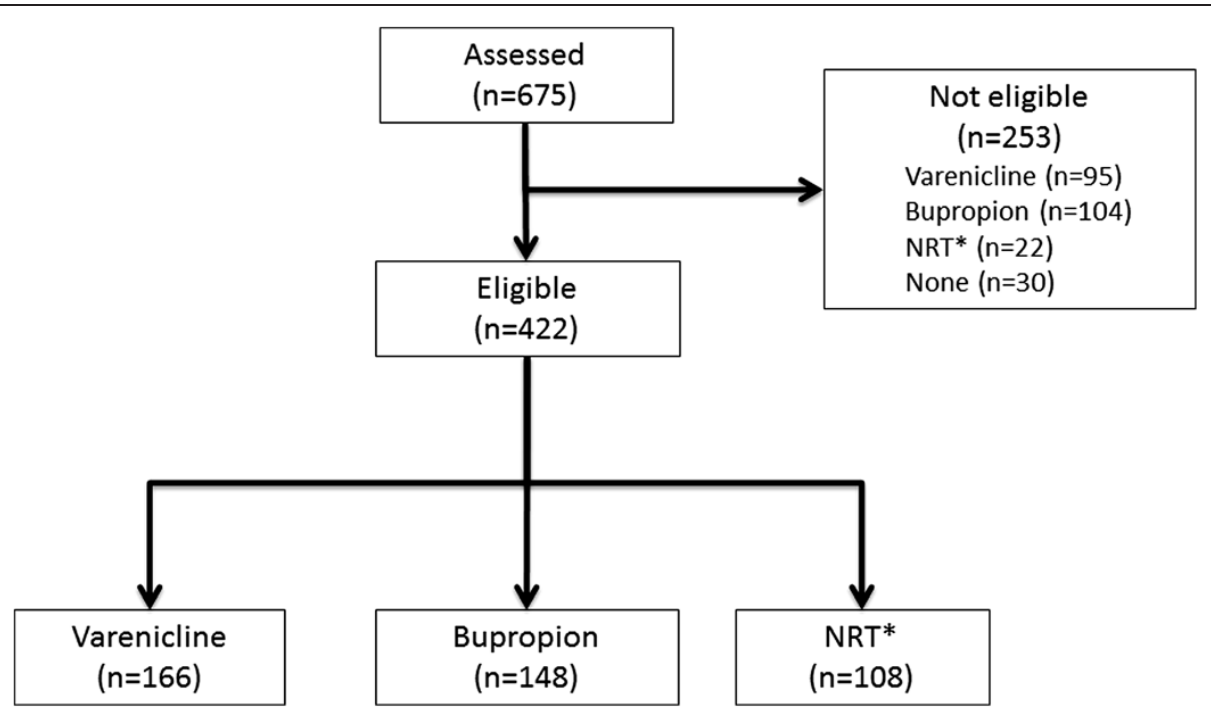

Figure 1 Study diagram. *NRT, Nicotine replacement therapy. 
Table 1 Patients' characteristics at admission

\begin{tabular}{|c|c|c|c|c|}
\hline & Treatments & & & \\
\hline Parameters & Varenicline $(n=166)$ & Bupropion $(n=148)$ & $\mathrm{NRT}(\mathrm{n}=108)$ & $p$ \\
\hline Age, years (mean $\pm S D$ ) & $39 \pm 9$ & $36 \pm 11$ & $38 \pm 12$ & 0.86 \\
\hline Female/Male & $36 / 130$ & $37 / 111$ & $30 / 78$ & 0.50 \\
\hline Smoking start age, years & $16 \pm 4$ & $16 \pm 5$ & $16 \pm 5$ & 0.92 \\
\hline Cigarettes pack/day, mean $\pm S D$ & $1.4 \pm 0.56$ & $1.2 \pm 0.47$ & $1.1 \pm 0.53$ & 0.003 \\
\hline Smoking pack/years & $30.3 \pm 20.9$ & $22.9 \pm 15.9$ & $25.1 \pm 18.6$ & 0.001 \\
\hline \multicolumn{5}{|l|}{ mean $\pm S D$} \\
\hline \multicolumn{5}{|l|}{ Smoking start reasons } \\
\hline Imitating/curiosity & $70 / 57$ & $74 / 43$ & $38 / 45$ & 0.02 \\
\hline Marital status (Single/Married) & $21 / 145$ & $36 / 112$ & $19 / 89$ & 0.02 \\
\hline Patient request to quit smoking & 158 & 146 & 103 & 0.08 \\
\hline Educational status & 45 & 33 & 37 & 0.04 \\
\hline Primary school & 55 & 49 & 37 & \\
\hline High school & 66 & 66 & 34 & \\
\hline \multicolumn{5}{|l|}{ University } \\
\hline FTND score, mean \pm SD & $7.1 \pm 2.4$ & $6.4 \pm 2.4$ & $5.4 \pm 2.6$ & 0.001 \\
\hline
\end{tabular}

FTND; Fagerström test for nicotine dependence.

difference between groups in smoking habit at time of admission to the clinic. Smoking pack/day, pack/years and FTND were highest in the varenicline group $(\mathrm{p}<0.001)$. The patients' characteristics are shown in Table 1.

The overall smoking cessation rate after 1 year was 35\%. The smoking cessation rates for varenicline, bupropion and NRT were $32.5 \%, 23 \%$, and $52.8 \%$, respectively, and were statistically significant $(\mathrm{p}<0.001)$ (Table 2$)$.

Due to differences among treatment groups in patient's smoking habits at the time of admission, logistic regression analysis was conducted with factors affecting smoking cessation success rates. Age, marital status, education level, age at smoking onset, reason for beginning to smoke, history of cessation, smoking pack/years, cigarette pack/ day, and FTND score did not have a positive or negative effect $(\mathrm{p}>0.05)$. Being male had a positive effect on success $(p=0.01)$; treatment type also had a significant effect on success $(\mathrm{p}<0.001)$ (Table 3$)$.

The overall relapse rate was $21.6 \%$. The relapse rates for varenicline, bupropion and NRT groups were $22.9 \%$, $32 \%, 5.6 \%$, respectively and were statistically significant

Table 2 Rates of quit smoking and relapse according to treatments at the end of one year

\begin{tabular}{llllll}
\hline Treatments & \multicolumn{2}{c}{ Quit smoking } & & \multicolumn{2}{c}{ Relapse } \\
\cline { 2 - 3 } \cline { 6 - 6 } & $\mathbf{N}$ & $\%$ & & N & $\%$ \\
\hline Varenicline & $\mathbf{5 4}$ & $\mathbf{3 2 . 5}$ & & $\mathbf{3 8}$ & $\mathbf{2 2 . 9}$ \\
Bupropion & 34 & 23 & & 47 & 32 \\
NRT & $\mathbf{5 7}$ & $\mathbf{5 2 . 8}$ & & $\mathbf{6}$ & $\mathbf{5 . 6}$ \\
\hline
\end{tabular}

NRT, Nicotine replacement treatment. $(\mathrm{p}<0.001)$ (Table 2). The most frequent factors leading to relapse were lack of determination (29.4\%), social pressure $(22.9 \%)$ and stress $(9 \%)$.

\section{Discussion}

This study showed that, besides behavioral therapy, pharmacologic treatment is important in smoking cessation success rates. It was found that NRT is the most efficient pharmacotherapy agent for smoking cessation. Relapses remained a major problem in the smoking cessation process. The bupropion group showed the highest relapse rate compared to varenicline and NRT groups, and lack of determination was the most important factor associated with relapse.

Smoking cessation is physically and psychologically challenging. Most smokers desire to quit, but without assistance the success rate is very low $(4-7 \%)[4,5]$. Intervention options to aid smokers in cessation are few. Interventions which include both behavioral and pharmacological therapy have been shown to be most effective,

Table 3 Factors affecting success in quit smoking

\begin{tabular}{ll}
\hline Factors & $\mathbf{p}$ \\
\hline Age & 0.99 \\
Smoking pack/years & 0.20 \\
Smoking pack/day & 0.41 \\
FTND score & 0.11 \\
Sex & 0.01 \\
Treatments & $<0.001$
\end{tabular}

FTND; Fagerström test for nicotine dependence. 
with success rates between 22 and 45\% [11-15]. In the current study, the success rate was $35 \%$.

Recently a meta-analysis demonstrated that varenicline, bupropion and NRT were all more effective than placebo in promoting smoking abstinence at one year $[8,16]$. Varenicline, the most recent pharmacologic therapy for smoking cessation, has been available since 2006. It exerts its effect as a nicotinic receptor antagonist. In two wide ranging, multicenter, double blind, phase III, randomized clinical studies, varenicline was shown to be safe and effective in promoting both continuous abstinence and long-term cessation [9,17]. Gonzales et al. compared varenicline and placebo at the end of three months and found that cessation rates were $44 \%$ and $18 \%$, respectively (OR:3.85, 95\% CI: 2.70-5.50) [9]. In the same study, the comparison of success rates between bupropion and varenicline groups was not statistically different, although varenicline was found to be more effective than the other drug (21.9\% vs 16.1\%, OR: 1.46, 95\% CI: 0.99-2.17). In studies comparing varenicline to NRTs, varenicline was found to be significantly more effective than a standard dose of NRT (56\% vs $43 \%$, respectively; OR: 1.70$)[18,19]$. However, in studies using combined NRTs (such as nicotine patch plus nicotine gum or nasal spray), varenicline and NRT showed comparable results (NRT: 37\%; varenicline: 33\%) [4]. In the current study, NRT was significantly more effective than varenicline based on patients' smoking cessation rates at one year $(32.5 \%$ vs. $52.8 \%)$. This result suggests that NRTs may be a cost-effective first-line treatment.

Buproprion SR was the first nicotine-free drug that was proven to help fight nicotine addiction. It exerts its effect by blocking the release of dopamine and noradrenaline and inhibiting nicotinic acetylcholine receptors [20]. In randomized-control studies bupropion was found to be twice as effective as placebo in aiding smoking cessation [20]. In another study, at 6 months the smoking cessation rate of the bupropion group was higher (27\%) than that $(16 \%)$ of the placebo group [21]. When bupropion treatment was combined with behavioral therapy, the smoking cessation rate at one year was found to be twice that of the placebo group [22].

Clinical trials have demonstrated significantly higher rates of smoking cessation for varenicline than for bupropion $[9,10,17]$, though a recent meta-analysis has demonstrated the superiority of bupropion to standard doses of NRT in promoting cessation at both three months and one year [16]. However, when bupropion was compared to NRTs, there was no significant difference in cessation rates at one year. In the current study, NRT was found to be more effective than bupropion $(52.8 \%$ vs. $23 \%)$. The combination of NRT and behavioral therapy may explain the increase in success rates. The fact that the success rates of all treatment groups at one year were higher in the current study than those reported in the literature may be attributable to the concurrent use of behavioral therapy.

Relapse is a major problem for people attempting to quit smoking. It has been observed that pharmacotherapy has a limited effect on preventing patients from resuming smoking. Treatment with NRTs has been shown to more effectively aid initial abstinence compared to bupropion [23]. In studies that have attempted to prevent relapse by prolonging varenicline and bupropion treatment, only varenicline showed a preventative effect [24]. In the current study, the highest rate of relapse was in the bupropion group (32\%). The main factors leading to relapse were the patients' lack of determination and social pressure. This suggests that the ability of pharmacotherapy to prevent relapse is limited.

Although the retrospective study design has some limitations, analyzing the clinical outcomes of real-life treatment options provides valuable information for future therapeutic practices.

\section{Conclusions}

In conclusion, NRTs can be used as the first treatment choice in the absence of contraindications. Factors leading to relapses require further assessment, and tailored behavioral therapy might be considered to deal with relapses.

\section{Competing interest}

The authors declare that they have no competing interests.

\section{Authors' contributions}

EYU, Assistant Professor Doctor, data analysis, design of the study. OA, Assistant Professor Doctor, acquisition of data. NY, Specialist, acquisition of data. MA, Professor Doctor, edit manuscript. MM, Professor Doctor, acquisition of data. HK, Professor Doctor, acquisition of data. LS, Professor Doctor, edit manuscript. All authors read and approved the final manuscript.

Received: 28 November 2013 Accepted: 15 January 2014

Published: 4 February 2014

\section{References}

1. WHO tobacco free initiative: Building Blocks for Tobacco Control: A Handbook. Geneva Switzerland: World WHO organization; 2004.

2. Mathers CD, Loncar D: Projection of global mortality and burden of disease from 2002 to 2030. Plos Med 2006, 3:e442.

3. Asaria P, Chisholm D, Mathers C, Ezzati M, Beaglehole R: Chronic disease prevention: health effects and financial costs of strategies to reduce salt intake and control tobacco use. Lancet 2007, 370:2044-2053.

4. Fiore MC, Jaen CR, Baker TB, Bailey WC, Benowitz NL, Curry SJ, Dorfman SF, Froelicher ES, Goldstein MG, Healton CG, Henderson PN, Heyman RB, Koh HK, Kottke TE, Lando HA, Mecklenburg RE, Mermelstein RJ, Mullen PD, Orleans CT, Robinson L, Stitzer ML, Tommasello AC, Villejo L, Wewers ME: Treating Tobacco Use and Dependence: 2008 Update: Clinical Practice Guideline. Rockville, MD: Public Health Service, US Dept of Health and Human Services; 2008.

5. Hurt RD, Ebbert JO, Hays JT, McFadden DD: Treating tobacco dependence in a medical setting. CA Cancer J Clin 2009, 59:314-326.

6. Wu P, Wilson K, Dimoulas P, Mills El: Effectiveness of smoking cessation therapies: a systematic review and meta-analysis. BMC Public Health 2006, 6:300.

7. Herman Al, Sofuoglu M: Comparison of available treatments for tobacco addiction. Curr Psychiatry Rep 2010, 12:433-440.

8. Eisenberg MJ, Fillion KB, Yavin D, Belisle P, Mottillo S, Joseph L, Gervais A O'Loughlin J, Paradis G, Rinfret S, Pilote L: Pharmacotherapies for smoking cessation: a meta-analysis of randomized controlled trials. CMAJ 2008, 179:135-144. 
9. Gonzales D, Rennard SI, Nides M, Oncken C, Azoulay S, Billing CB, Watsky EJ, Gong J, Williams KE, Reeves KR, Varenicline Phase 3 Study Group: Varenicline, an alpha4beta2 nicotinic acetylcholine receptor partial agonist, vs sustained-release bupropion and placebo for smoking cessation: a randomized controlled trial. JAMA 2006, 296:47-55.

10. Nides M, Oncken C, Gonzales D, Rennard S, Watsky EJ, Anziano R, Reeves KR: Smoking cessation with varenicline, a selective alpha4beta2 nicotinic receptor partial agonist: results from a 7-week, randomized, placebo and bupropion controlled trial with 1-year follow-up. Arch Intern Med 2006, 166:1561-1568.

11. Solak ZA, Telli CG, Erdinc E: The results of smoking cessation treatments. Turkish Thoracic J 2003, 4:73-77.

12. Uzaslan EK, Ozyardımci N, Karadag M, et al: The physician's intervention in smoking cessation: Results of the five years of smoking cessation clinic. Ann Med Sci 2000, 9:63-69.

13. Can G, Oztuna F, Ozlü T: The evaluation of outpatient smoking cessation clinic results. Tuberk Toraks 2004, 52:63-74.

14. Demir T, Tutluoğlu B, Koç N, Bilgin L: One-year follow up results of smoking cessation outpatient clinic. Tuberk Toraks 2004, 52:63-68.

15. Salepci B, Fidan A, Oruc O, Torun E, et al: Success rates in our smoking cessation clinic and factors affecting it. Turkish Thoracic J 2005, 6:151-158

16. Mills EJ, Wu P, Lockhart I, Thorlund K, Puhan M, Ebbert JO: Comparisons of high-dose and combination nicotine replacement therapy, varenicline, and bupropion for smoking cessation: a systematic review and multiple treatment meta-analysis. Ann Med 2012, 44:588-597.

17. Jorenby DE, Hays JT, Rigotti NA, Azoulay S, Watsky EJ, Williams KE, Billing CB, Gong J, Reeves KR, Varenicline Phase 3 Study Group: Efficacy of varenicline, an alpha4beta2 nicotinic acetylcholine receptor partial agonist, vs placebo or sustained-release bupropion for smoking cessation: a randomized controlled trial. JAMA 2006, 296:56-63.

18. Stapleton JA, Watson L, Spirling LI, Smith R, Milbrandt A, Ratcliffe M, Sutherland $\mathrm{G}$ : Varenicline in the routine treatment of tobacco dependence: a pre-post comparison with nicotine replacement therapy and an evaluation in those with mental illness. Addiction 2008, 103:146-154.

19. Aubin HJ, Bobak A, Britton JR, Oncken C, Billing CB Jr, Gong J, Williams KE, Reeves KR: Varenicline versus transdermal nicotine patch for smoking cessation: results from a randomized, open label trial. Thorax 2008, 63:717-724. doi:10. 1136/thx.2007.090647.

20. Jimenez RC: Pharmacological treatment for smoking cessation. Eur Respir Mon 2008, 42:7497.

21. Roddy E: Bupropion and other nonnicotine pharmacotherapies. BMJ 2004, 328:509-511.

22. Aubin $\mathrm{HJ}$ : Tolerability and safety of sustained-release bupropion in the management of smoking cessation. Drugs 2002, 62:45-52.

23. Japuntich SJ, Piper ME, Leventhal AM, Bolt DM, Baker TB: The effect of five smoking cessation pharmacotherapies on smoking cessation milestones. J Consult Clin Psychol 2011, 79:34-42.

24. Hajek P, Stead LF, West R, Jarvis M, Lancaster T: Relapse Prevention Interventions for Smoking Cessation (Review). Published by John Wiley \& Sons, Ltd: The Cochrane Collaboration; 2009. http://www.thecochranelibrary.com.

doi:10.1186/2049-6958-9-9

Cite this article as: Yilmazel Ucar et al: Effectiveness of pharmacologic therapies on smoking cessation success: three years results of a smoking cessation clinic. Multidisciplinary Respiratory Medicine 2014 9:9.

\section{Submit your next manuscript to BioMed Central and take full advantage of:}

- Convenient online submission

- Thorough peer review

- No space constraints or color figure charges

- Immediate publication on acceptance

- Inclusion in PubMed, CAS, Scopus and Google Scholar

- Research which is freely available for redistribution 